\title{
SAÚDE GLOBAL E DIREITOS HUMANOS: 0 PRIMEIRO CASO SUSPEITO DE EBOLA NO BRASIL
}

Deisy Ventura

Professora do Instituto de Relações Internacionais e da Faculdade de Saúde Pública da USP;

bolsista de Produtividade em Pesquisa do CNPq. São Paulo, SP. Brasil.

Emails: <deisyflv@gmail.com><deisy.ventura@usp.br>

Vivian Holzhacker

Mestre em Direito Internacional dos Direitos Humanos pela Universidade de Connecticut. Coordenadora de Proteção e Advogada da Caritas Arquidiocesana de São Paulo(2011-2014) e Consultora do Alto Comissariado da ONU para Refugiados- ACNUR (2015). São Paulo, SP. Brasil.

Email:<vivian.holz@gmail.com>

http://dx.doi.org/10.1590/ 0102-6445107-140/98

A recente epidemia de Ebola ocorrida na África Ocidental (2014-2015) constitui um privilegiado laboratório para o estudo da saúde global sob a perspectiva dos direitos humanos. Entre as diversas dimensões do fenômeno, destacamos duas grandes agendas de pesquisa.

A primeira delas compreende os estudos emergentes sobre a relação entre Ebola e direitos humanos nas regiões mais atingidas. A rápida disseminação da doença deriva em grande parte da escassa efetividade dos direitos humanos, em especial a relacionada à pobreza, à dificuldade de acesso a tratamento e medicamentos, à falta de saneamento básico e água potável, além da urbanização desordenada. Destacam-se as publicações sobre o fracasso da cooperação internacional para o desenvolvimento no campo da saúde (Kerouedan, 2015) e o papel das instituições financeiras internacionais no desmantelamento dos sistemas nacionais de saúde dos Estados mais atingidos (Kentikelenis et al., 2015). Além do significativo impacto sobre o direito à vida e à saúde, a crise sanitária engendrou outros tipos de violação, a exemplo das medidas 
quarentenárias em condições desumanas e degradantes adotadas pela Libéria na favela de West Point, em Monróvia; ou as chamadas "leis anti-Ebola", adotadas pelo Parlamento de Serra Leoa, que criminalizaram, entre outras condutas, a omissão em informar às autoridades a existência de parentes ou vizinhos doentes.

A segunda grande agenda de pesquisa aborda a repercussão da recente epidemia fora de seu epicentro. Desde 2007, com a vigência do novo Regulamento Sanitário Internacional (RSI), o combate à propagação internacional de doenças específicas deu lugar a uma nova categoria político-jurídica, a Emergência Sanitária de Importância Internacional (ESPII). Quando uma ESPII é declarada pela OMS, instaura-se uma espécie de transversalidade da emergência, no sentido de que é deflagrada uma complexa engrenagem entre as recomendações internacionais e as medidas adotadas pelos governos 108 nacionais, com ampla repercussão nos meios de comunicação (Ventura, 2013). Em relação à epidemia de Ebola, a ESPII foi declarada em agosto de 2014 (OMS, 2014) e perdurou até março de 2016 (OMS, 2016a).

Na Guiné, na Libéria e em Serra Leoa, países mais atingidos pela epidemia, foram notificados 28.646 casos confirmados, prováveis ou suspeitos, e 11.323 óbitos até março de 2016; no mesmo período, no Ocidente, foram notificados 7 casos confirmados, prováveis ou suspeitos 4 nos Estados Unidos e casos individuais na Espanha, na Itália e no Reino Unido - dos quais apenas 1 óbito (OMS, 2016b). Diversos tipos de violação de direitos humanos foram noticiados à época, entre os quais citamos a restrição do ingresso de pessoas oriundas da África Ocidental em países como a Austrália e o Canadá; nos Estados Unidos, a sentença judicial que manteve em parte as restrições impostas pelo governo do Estado do Maine a uma enfermeira norte-americana que havia trabalhado na África 
Ocidental, inclusive manter a distância de 1 metro em relação a outras pessoas em locais públicos; na Inglaterra, a limitação do acesso de profissionais da saúde ao transporte coletivo.

O presente artigo situa-se nesse segundo campo de estudos, buscando aferir o impacto da crise sanitária gerada pelo vírus Ebola sobre os direitos humanos de um solicitante de refúgio considerado o primeiro caso suspeito de Ebola no Brasil. O estudo desse caso justifica-se porque, embora não confirmado, ele alcançou grande repercussão nacional e, em nossa opinião, seu desenrolar torna explícito o grande potencial de impacto das emergências sanitárias internacionais sobre os direitos humanos.

Apresentaremos o caso sob o prisma do, à época, paciente, com base na entrevista que ele nos concedeu pessoalmente em São Paulo (SP), em 16 de julho de 2015. Como abordagem qualitativa, adotamos a entrevista compreensiva que combina características da entrevista semidiretiva com as da entrevista etnográfica, para obter um discurso mais narrativo do que informativo (Kaufmann, 2013; Ferreira, 2014). Esse tipo de entrevista busca a configuração de um encontro em que uma pessoa solicita a palavra de outra sobre certo tema, reconhecendo o direito do entrevistado à subjetividade autônoma (Matthey, 2005). Assim, pedimos a John que nos contasse sua história, e nossas perguntas limitaram-se a tentar compreender melhor a sua fala. A língua materna de John é o fula e, à época da entrevista, John não falava português, embora frequentasse um curso básico do idioma. A entrevista nos foi concedida em inglês, mas aparecem na fala do entrevistado algumas palavras em fula (não citadas no presente artigo) e em português. Optamos por não traduzir literalmente as citações da entrevista no decorrer do texto, por entendermos que a escolha das palavras em inglês por John é relevante para a interpretação de sua narrativa 
pelos leitores ${ }^{1}$. As citações indiretas foram imprescindíveis tanto pela limitação de espaço do artigo como pela complexidade do texto transcrito que dificultaria sua compreensão, buscando, porém, a maior fidelidade possível ao que nos foi transmitido durante o encontro.

A fim de proteger sua identidade, o entrevistado solicitou ser chamado pelo pseudônimo John. Com o intuito de complementar um trecho de seu relato, entrevistamos por telefone, em 2 de outubro de 2015, a funcionária pública federal que se encarregou do traslado de John do Rio de Janeiro (RJ) a São Paulo (SP), quando de sua alta hospitalar. Protegemos a identidade dessa funcionária sob o pseudônimo de Ana.

Na primeira seção do artigo, John apresenta-se como refugiado e relata cronologicamente o que aconteceu desde sua partida da Guiné até a chegada ao Rio de Janeiro, fazendo emergir a possibilidade de que tenham ocorrido violações aos seus direitos como paciente quando de seu primeiro atendi110 mento no Brasil. Na segunda seção, a narrativa de John concentra-se na repercussão que o seu caso alcançou nos meios de comunicação e como ele lidou com sua súbita notoriedade após deixar o hospital. Acrescentamos às transcrições de sua entrevista o testemunho de Ana, que elucida as condições peculiares em que John saiu do hospital, permitindo concluir que a ampla difusão da identidade e da imagem de John constituem flagrantes violações da legislação brasileira e do direito internacional. Finalmente, a terceira seção apresenta dois aspectos da repercussão do primeiro caso suspeito de Ebola no Brasil: uma que constitui um obstáculo à efetividade dos direitos humanos, qual seja, o amálgama entre o caso suspeito e o tema das migrações e do refúgio; e outra que contribui para a efetividade dos direitos humanos, como as iniciativas da Defensoria Pública da União e do Ministério Público Federal.

\footnotetext{
${ }^{1}$ Porém, para seguir orientações editoriais desta publicação, fizemos tradução livre desses trechos em notas de rodapé.
} 


\section{"Eles transformaram em outra doença": violações do direito à informação e ao consentimento}

Filho de guineenses, John nasceu em 1967, na capital de Serra Leoa, Freetown. Mudou-se para Guiné Conacri pouco antes do início da guerra civil serra-leonina ${ }^{2}$. Apesar de ter residido por mais de vinte anos na Guiné, cujo idioma oficial é o francês, preferiu conceder-nos a entrevista em inglês, idioma em que completou o ensino médio ainda em Serra Leoa. John conta que vivia na capital da Guiné Conacri, mas teve de deixar o país por sofrer perseguição étnica promovida pelo atual governo ${ }^{3}$. John é muçulmano e pertence à etnia fula. Possuía uma loja de roupas que foi atacada e queimada, tendo o incêndio causado a morte de sua esposa e de sua filha.

Chegou ao Brasil regularmente, com visto de turista, em 19 de setembro de 2014, na capital de São Paulo. A seguir, dirigiu-se à cidade de Cascavel (PR), onde supostamente teria mais facilidade para obter documentos brasileiros, segundo conterrâneos que encontrou no país. Mas foi em Dionísio Cerqueira (SC) que apresentou à Polícia Federal a solicitação do reconhecimento de seu status de refugiado. No Brasil, em virtude do artigo $1^{\circ}$ da Lei ${ }^{\circ} 9.474$, de 1997 ,

\footnotetext{
${ }^{2}$ Particularmente atroz, essa guerra durou de 1991 até 2002. Contando com o financiamento de empresas multinacionais extratoras de diamantes, deixou um balanço de 100 a 200 mil mortos e mais de 2 milhões de deslocados forçados; milhares de casos de estupro, escravidão sexual e sequestro, além da utilização massiva de crianças-soldados (Niang, 2014).

${ }^{3}$ Incontáveis relatórios de Estados, de organizações internacionais e de organizações não governamentais corroboram a descrição da situação política feita por John, em particular do agravamento das tensões étnicas a partir das eleições legislativas de 2013. Em síntese, desde a ascensão de Alpha Condé à presidência da Guiné, em 2010, com ampla sustentação política da etnia mandinga, o poder vem sendo exercido de modo a discriminar os grupos étnicos rivais, sendo o principal deles a etnia fula, com a repressão violenta de manifestações políticas, além de saques e pilhagens nos bairros de maioria fula, a fim de prejudicar suas atividades econômicas, com o beneplácito das forças de segurança estatais (Armed..., 2015; Bélgica, França e Suíça, 2012; Canadá, 2014; Estados Unidos, 2015; União Europeia, 2013).
} 
"será reconhecido como refugiado todo indivíduo" que "devido a fundados temores de perseguição por motivos de raça, religião, nacionalidade, grupo social ou opiniões políticas encontre-se fora de seu país de nacionalidade e não possa ou não queira acolher-se à proteção de tal país" (Brasil, 1997).

O reconhecimento da situação de refugiado depende, porém, de processo administrativo longo e complexo, que tramita principalmente no âmbito do Comitê Nacional para Refugiados do Ministério da Justiça (Conare). Todavia, ao solicitar refúgio, a Polícia Federal emite protocolo provisório que torna regular a estada do solicitante no país até a decisão final do Conare, permitindo a obtenção de Carteira de Trabalho e Previdência Social (CTPS) e do Cadastro de Pessoas Físicas (CPF). De posse desses documentos, John obteve uma entrevista de emprego em uma empresa de corte de frango em Cascavel. Temia não estar à altura do desem112 penho exigido no futuro emprego, pois contraiu malária quando ainda vivia na Guiné Conacri e, embora tenha seguido o tratamento prescrito, sentia-se fraco e sem apetite, e percebeu também que sua língua havia escurecido ${ }^{4}$.

John buscou então atendimento médico no Hospital Morumbi $i^{5}$, em Cascavel, no dia 9 de outubro de 2014 pela

\footnotetext{
${ }^{4}$ Segundo o boletim epidemiológico oficial, "o paciente referiu que em agosto de 2014, antes de sua vinda ao Brasil, apresentou um quadro de febre, mialgia e adinamia, tendo sido diagnosticado com malária e tratado com medicação que não soube precisar. Após o tratamento, percebeu alteração de cor em sua língua e perda do paladar, além de uma hiperpigmentação na pele em região palmoplantar, com acometimento ungueal" (Brasil/MS/SVS, 2016, p. 3).

${ }_{5}^{5}$ Dito em inglês, "Morumbi Hospital" (John, 7:20). Entre as unidades do Sistema Único de Saúde (SUS) em Cascavel, existe de fato uma Unidade de Saúde da Família com o nome de Morumbi (USF-Morumbi). No entanto, segundo as autoridades federais, estaduais e municipais, John teria sido atendido pela Unidade de Pronto Atendimento Brasília (UPA-Brasília), no dia 9 de outubro, no período da tarde (Protocolo internacional..., 2014; Brasil/MS/SVS, 2016). Em conversa informal, por telefone, com um agente da USF-Morumbi, fomos informadas de que a UPA-Brasília seria a unidade de pronto-atendimento mais próxima do bairro Morumbi e provavelmente John tenha se referido a um hospital do Morumbi.
} 
manhã. Quando atendido, fez referência explícita à malária e aos sintomas de falta de apetite e escurecimento da língua. Para comunicar-se, foi ajudado por uma mulher que falava inglês. Após algumas horas, foi chamado novamente e atendido por outro médico, a quem repetiu seu relato original. O médico aferiu sua temperatura e sua pressão arterial, e a seguir prescreveu um exame de sangue, indicando suspeita de disfunção hepática. John relatou que não teve febre nem vômito. Foi levado a um laboratório, onde lhe disseram que deveria aguardar. Transcorridas mais algumas horas, cogitou ir embora, mas para tanto seria preciso recuperar seus documentos (passaporte e solicitação de refúgio) que foram entregues à triagem. Ao perguntar o que estava acontecendo, alguém lhe disse para aguardar, mas nada lhe foi explicado: "The woman told me 'espera, espera'. They didn't told me anything. I couldn't leave because they had my documents" ${ }^{" 6}$ (John, 2015, 14:32) ${ }^{7}$.

Quando decidiu ir embora e pediu seus documentos, disseram-lhe que ele finalmente seria atendido. Foi levado a um quarto onde passou a receber soro. John reclama: "I watched the drip, it was very slow. I asked myself: How long am I staying here? If I were sick, it would have to move

\footnotetext{
6 “A mulher me disse 'espera, espera'. Eles não me disseram nada. Eu não pude ir embora porque eles estavam com meus documentos."

7 Segundo o boletim epidemiológico oficial, "no dia 9 de outubro [de 2014], [John] procurou assistência na UPA-Brasília por volta das 10h15, com queixa de alterações na língua, hiporexia com perda ponderal não quantificada e adinamia, com evolução de aproximadamente dois meses, associados a cefaleia e sensação de febre, percebida no dia anterior (início dos sintomas em 8 de outubro de 2014, para efeito de investigação da suspeita de Ebola). Não houve aferição de temperatura durante o atendimento. O paciente referiu ter chegado à unidade de saúde sozinho e caminhando. O hemograma realizado durante o exame admissional para vínculo empregatício em uma empresa privada (amostra colhida em 8 de outubro, data anterior à de início dos sintomas) apresentou uma leucopenia, uma anemia moderada, além de anisocitose e macrocitose. Ressalta-se que esse exame foi coletado anteriormente à suspeita de Ebola. No dia 10 de outubro, por volta das $5 \mathrm{~h}$, o paciente foi removido para o INI da Fiocruz/MS, no Rio de Janeiro/RJ" (Brasil/MS/SVS, 2016, p. 4).
} 
much faster" (John, 2015, 16:12). Logo, John percebeu que a porta estava trancada. Após algum tempo, trouxeram-lhe comida.

À noite, disseram a John que ele iria ao Rio de Janeiro. Como o médico havia suspeitado de um problema no fígado, pensou que iria para o Rio para ser tratado: "I asked why, and they said I was going to be treated there. I thought I had a liver problem. They were all using that diver clothes. They gave me one like that and said, let's go"9 (John, 2015, 16:30). John conta então que todos ao seu redor vestiam "roupas de mergulhadores" e ele também teve de vesti-las. Embora tenha insistido que poderia caminhar, foi obrigado a ficar deitado. Foi levado de ambulância ao aeroporto, em uma viagem que teria durado cerca de uma hora. Pouco pôde ver do que estava ocorrendo, pois estava deitado. Uma vez chegado ao aeroporto, levaram-no de maca ao avião. Tentou abrir a janela da pequena aeronave, mas não lhe foi 114 permitido. Mal permitiam que se movesse.

Já era madrugada quando John chegou ao Instituto Nacional de Infectologia Evandro Chagas da Fundação Oswaldo Cruz (INI-Fiocruz), no Rio de Janeiro (RJ). O médico que o acolheu perguntou se ele sabia por que estava ali. Diante da negativa de John, contou sobre a suspeita de Ebola. Nas palavras do paciente:

The doctor asked me if I knew why I was there. I said no. He said they suspected I have Ebola. I panicked. What, Ebola? I don't have Ebola! The doctor asked me if I had fever, vomit or diarrhea. I said no. My problem was the appetite

\footnotetext{
8 "Eu olhei o gotejamento, estava muito devagar. Eu me perguntei: por quanto tempo vou permanecer aqui? Se eu estivesse doente, teria que se mover mais rápido."

9 "Perguntei por quê, e me responderam que eu seria tratado lá. Pensei que tinha um problema no fígado. Eles estavam usando aquelas roupas de mergulhador. Me deram uma como aquela e disseram vamos."
} 
and black tongue. I know that symptoms of Ebola is vomiting and diarrhea. I saw people with Ebola on TV ${ }^{10}$ (John, 2015, 22:27).

John conta que, na Guiné, sempre que alguém vomita, todos que estão em volta afastam-se correndo. Os sintomas da doença são amplamente divulgados pelos meios de comunicação. Logo, John estava consciente de que não tinha Ebola. O médico do Rio de Janeiro explicou-lhe que fariam um primeiro teste e, em caso de resultado negativo, o teste seria repetido no dia seguinte. Recomendou a John que ficasse tranquilo, pois não apresentava os sintomas da doença, mas, uma vez deflagrado o protocolo de resposta para Ebola, o pessoal médico seria obrigado a fazer o seu trabalho. E esclareceu que independentemente do resultado, John seria tratado. Enfim, o paciente entendia o que estava ocorrendo: "I was put in suspension, they didn't explain me what was happening. I didn't like the treatment in Cascavel"11 (John, 2015, 22:27). Já no Rio de Janeiro, afirma ter se sentido respeitado e bem tratado.

Cabe então aferir se o relato de John permite identificar violações dos seus direitos. $\mathrm{O}$ direito das pessoas assistidas à informação sobre sua saúde é um dos princípios do Sistema Único de Saúde (Brasil, 1990, art. 7, V). Embora os direitos do paciente não estejam codificados em um só documento, podem ser encontrados principalmente na Constituição Federal; nos códigos civil, penal e de defesa do consumidor; no Estatuto da Criança e do Adolescente e no Estatuto do Idoso; nos códigos de ética das profissões da saúde; em

\footnotetext{
10 "O médico perguntou se eu sabia porque estava lá. Eu disse não. Ele disse que suspeitavam que eu tinha Ebola. Entrei em pânico. O quê? Ebola? Eu não tenho Ebola! O médico perguntou se eu estava com febre, vômito ou diarreia. Eu disse não. Meu problema era apetite e língua preta. Sei que os sintomas de Ebola são vômito e diarreia. Vi pessoas com Ebola na televisão."

11 "Me puseram em suspenso, não me explicaram o que estava acontecendo. Não gostei do tratamento em Cascavel."
} 
resoluções do Conselho Federal de Medicina, declarações internacionais de princípios, normas do Ministério da Saúde, legislação esparsa e jurisprudência (Gomes et al., 2008). Porém, não encontramos base legal que possa justificar a violação do direito à informação no caso de John.

Em virtude da Portaria do Ministério da Saúde $n^{\circ} 1.820$, de 2009, que dispõe sobre os direitos e deveres dos "usuários da saúde", é direito de toda pessoa ter

[...] informações sobre o seu estado de saúde, de maneira clara, objetiva, respeitosa, compreensível quanto a: a) possíveis diagnósticos; [...] c) tipos, justificativas e riscos dos exames solicitados; [...] e) objetivos, riscos e benefícios de procedimentos diagnósticos, cirúrgicos, preventivos ou de tratamento; f) duração prevista do tratamento proposto; [...] j) duração prevista dos procedimentos e tempo de recuperação; k) evolução provável do problema de saúde 116 (Brasil/MS, 2009, art. 3o parágrafo único, II).

A norma assegura ainda a "liberdade de procurar segunda opinião ou parecer de outro profissional ou serviço sobre seu estado de saúde ou sobre procedimentos recomendados, em qualquer fase do tratamento" (ibidem, art. $\left.5^{\circ}, \mathrm{IX}\right)$. Tais direitos também são explicitamente enunciados em documento de ampla difusão nacional, que é a Carta dos Direitos dos Usuários da Saúde (Brasil/MS, 2007).

Eles encontram eco igualmente no Código de Ética Médica vigente no país, que garante ao paciente o direito de "decidir livremente sobre a execução de práticas diagnósticas ou terapêuticas, salvo em caso de iminente risco de morte" (Conselho Federal de Medicina, 2009, art. 31) e veda ao médico "deixar de informar ao paciente o diagnóstico, o prognóstico, os riscos e os objetivos do tratamento, salvo quando a comunicação direta possa lhe provocar dano, devendo, nesse caso, fazer a comunicação a seu 
representante legal" (ibidem, art. 34). A doutrina elucida que a expressão "iminente risco de morte" deve ser entendida como caso em que não há tempo hábil para prestar ao paciente as informações e receber dele o consentimento (Dias, 2015). Quanto à hipótese de que a comunicação possa causar danos, ela jamais pode ser invocada pelo receio de que o paciente recusará o tratamento sugerido, pois isto desrespeitaria "a obrigação de respeitar a autonomia do paciente [que] requer, acima de tudo, habilitá-lo a [...] obter senão o controle desejado, pelo menos o maior controle possível" (Wanssa, 2011, p. 116).

Por outro lado, os serviços de saúde devem garantir "o consentimento livre, voluntário e esclarecido, a quaisquer procedimentos diagnósticos, preventivos ou terapêuticos, salvo nos casos que acarretem risco à saúde pública" (Brasil/MS, 2009, art. $\left.5^{\circ}, \mathrm{V}\right)$. A ressalva traz à baila a licitude de medidas restritivas de direitos como o isolamento e o tratamento obrigatório em caso de doenças transmissíveis de notificação compulsória como Ebola.

A legislação epidemiológica vigente, a Lei $\mathrm{n}^{\circ}$ 6.259, de 1975, foi elaborada em plena ditadura militar, o que explica a ausência de uma descrição detalhada das medidas restritivas de direitos que as autoridades sanitárias podem adotar (Brasil, 1975). Trata-se de "uma legislação anterior ao Sistema Único de Saúde e à própria Constituição Federal de 1988, não contemplando diversos aspectos que fazem sentido apenas no âmbito de um Estado Democrático de Direito" (Aith e Dallari, 2009, p. 120). Assim, as medidas de poder de polícia relacionadas à vigilância epidemiológica $^{12}$ parecem ser amparadas (ainda que vagamente) pela

\footnotetext{
${ }^{12}$ Em virtude do art. $7^{\circ}, \S 2^{\circ}$ da Lei no 8.080/90, a vigilância epidemiológica é "um conjunto de ações que proporcionam o conhecimento, a detecção ou prevenção de qualquer mudança nos fatores determinantes e condicionantes de saúde individual ou coletiva, com a finalidade de recomendar e adotar as medidas de prevenção e controle das doenças ou agravos" (Brasil, 1990).
} 
citada lei. Ela estabelece que em decorrência de resultados, parciais ou finais, de investigação epidemiológica, a autoridade sanitária tem a obrigação de "adotar, prontamente, as medidas indicadas para o controle da doença, no que concerne a indivíduos, grupos populacionais e ambiente" (Brasil, 1975, art. 12), ficando as pessoas físicas e as entidades públicas ou privadas abrangidas pelas eventuais medidas "sujeitas ao controle determinado pela autoridade sanitária” (art. 13).

Deduz-se que, entre as medidas que visam à contenção dos riscos sanitários, podem encontrar-se o isolamento, o tratamento compulsório, a quarentena, o cordão sanitário, entre outras. No entanto, por envolverem graves limitações aos direitos e liberdades individuais, elas deveriam ser previstas por legislação específica:

[...] as medidas de saúde pública podem, com efeito, 118 invadir a esfera da liberdade individual de forma bastante agressiva. No entanto, esta invasão, no âmbito do Estado Democrático de Direito, será sempre permitida quando feita nos termos da lei e em defesa do interesse público (Aith e Dallari, 2009, p. 121).

No plano internacional, o novo Regulamento Sanitário Internacional (RSI) - vigente desde 2007 em 196 países, inclusive no Brasil - contempla essa preocupação, ao menos no que atine aos direitos individuais. Embora recomende, em caso de emergência internacional e quando necessário, a implementação de medidas restritivas como o isolamento, a quarentena e o tratamento obrigatório, o RSI assegura em seu artigo $3^{\circ}$ : "a implementação deste Regulamento será feita com pleno respeito à dignidade, aos direitos humanos e às liberdades fundamentais das pessoas" (OMS, 2009). Estipula ainda, no artigo 32, que: "na implementação das medidas de saúde de que trata o 
presente Regulamento, os Estados Partes tratarão os viajantes com respeito à sua dignidade, direitos humanos e liberdades fundamentais e minimizarão qualquer incômodo ou angústia associado a tais medidas”. Em que pese a doença pelo vírus Ebola jamais tenha sido declarada emergência nacional no Brasil, sublinhamos que a norma regula que essas situações em nosso país, o Decreto $\mathrm{n}^{0} 7.616$, de 2011, não faz uma só referência aos direitos e garantias individuais (Brasil, 2011).

No mesmo diapasão, a detida análise do Plano de Contingência para Emergência em Saúde Pública - Doença pelo Vírus Ebola (Brasil/MS/SVS, 2014), cuja posição na hierarquia da ordem jurídica brasileira resta precisar, permite constatar que ele não refere direitos ou garantias individuais ao prever o isolamento e internação imediatos e o tratamento obrigatório do paciente. O plano de contingência (p. 22 e 23) prevê o dever de "orientar o paciente e familiares/acompanhantes sobre os procedimentos que serão adotados" apenas quando o paciente chega aos hospitais de referência estaduais e nacionais. No caso de John, transportado diretamente da unidade de pronto-atendimento ao hospital nacional de referência, foi o que de fato ocorreu: ele só obteve informações sobre seu estado e sobre o tratamento quando chegou ao Rio de Janeiro. Talvez a negligência em relação aos direitos do paciente se explique por uma percepção mais ampla que caracteriza a vigilância epidemiológica: "considerando a alta taxa de ataque secundário e a elevada taxa de letalidade da doença pelo vírus Ebola, do ponto de vista da saúde pública evitar a transmissão passa a ter maior impacto do que o próprio desfecho do caso índice" (Cerbino Neto, 2014, p. 2).

Não obstante, devemos lembrar que John não apresentava sintomas da doença, e que, segundo o Plano de Contingência brasileiro, 
A transmissão só ocorre após o aparecimento dos sintomas, e se dá por meio do contato com sangue, tecidos ou fluidos corporais de indivíduos infectados (incluindo cadáveres), ou do contato com superfícies e objetos contaminados. Não há transmissão durante o período de incubação. O risco de introdução da doença pelo vírus Ebola no Brasil é muito baixo, assim como a disseminação global e sustentabilidade da transmissão do vírus fora da África Ocidental (Brasil/ MS/SVS, 2014, p. 9).

O caso de John causa perplexidade adicional, pois "o tratamento obrigatório é uma situação-limite em saúde pública"; a ética médica o percebe como "medida heroica", em situações de iminente risco de morte (Santos e Nascimento, 2014, p. 183). Logo, o "Estado não dispõe de autorização ilimitada para impor um tratamento e privar de liberdade pacientes sob doença” (p. 183). Por outro lado, existe 120 um amplo questionamento científico acerca da eficácia das medidas coercitivas no combate às epidemias, especialmente da quarentena: "todos os níveis de evidência" relacionados aos seus resultados "mostram que é uma medida cara e que não reduz nem impede nem modifica o ciclo de uma epidemia” (p. 178).

Outro elemento em jogo quando da tomada dessas medidas é a sensação de segurança que se quer transmitir à população: "o isolamento compulsório precisa ser discutido na dimensão conceitual/legal e também na operacional, dentro de uma estratégia de comunicação" (Cerbino Neto, 2014, p. 1). Entretanto, "é preciso definir quais os mecanismos de contenção poderão ser utilizados e qual o anteparo legal para a sua utilização" (p. 1).

Como já propuseram Aith e Dallari (2009), a legislação brasileira deveria determinar que a eventual adoção de medidas restritivas de direito para combate a epidemias fosse comunicada ao Ministério Público e submetida a um 
órgão de revisão apto a "assegurar ao paciente o direito ao contraditório e verificar a real necessidade da medida", a exemplo do que determina a regulação da internação involuntária de pacientes psiquiátricos (Delgado, 2012, p. 79). Esse tipo de salvaguarda evitaria o uso abusivo de medidas restritivas, especialmente

[...] por profissionais não médicos, ocupantes de cargos civis do Estado, sob a pressão da possível gravidade de uma epidemia. Nesse ponto, a Saúde Pública não deve se omitir nem se mostrar ambígua diante dessa questão nociva, coercitiva e judicializante do complexo problema que é o enfrentamento e prevenção de epidemias (Santos e Nascimento, 2014, p. 183).

Dez meses após sua internação compulsória, quando de nosso encontro, John ainda não se conformava com o ocorrido.

Even now, when I think about it, how I came across this problem, I don't really understand it. I said I have no appetite and they transformed it to another sick. I know that Ebola is very dangerous. In Guinee, if they said someone had Ebola, this person was going to die. I didn't think I have it. I thought it could be another sickness that were disturbing me. I don't know why the doctor [em Cascavel] thought I had Ebola. Maybe because I come from Africa ${ }^{13}$ (John, 2015, 22:27).

\footnotetext{
13 "Mesmo agora, quando penso sobre isso, como me deparei com este problema, eu realmente não entendo. Eu disse que estava sem apetite e eles transformaram em outra doença. Eu sei que Ebola é muito perigoso. Na Guiné, se dissessem que alguém estava com Ebola, essa pessoa iria morrer. Eu não achava que tinha isso. Pensava que poderia ser outra doença me perturbando. Não sei por que o médico [em Cascavel] pensou que eu tinha Ebola. Talvez porque eu venho da África.”
} 
“Talvez porque eu venho da África...". Essa frase de John talvez explique igualmente a ostensiva divulgação de sua imagem pelos meios de comunicação, à revelia da lei, como veremos a seguir.

\section{Exposição pública da identidade: violação do direito sanitário e do direito dos refugiados}

No Rio de Janeiro, John conta que foi bem tratado, mas não estava feliz. Pediram que não desligasse a luz do quarto, pois seria observado continuamente pelas câmeras. Uma mulher foi ao seu quarto e ligou a televisão. Ele ouviu o próprio nome no telejornal da Rede Bandeirantes. Quando olhou para o aparelho, viu sua foto. Diziam que ele era o primeiro suspeito de Ebola no Brasil. Assim ele descreve o que viu: "I saw myself on TV, how they put me on the ambulance. They used my picture, I saw my protocol. After that, I put the television off, I didn't want to watch it" ${ }^{14}$ (John, 2015, 28:35). Ele guarda a

122 nítida lembrança do intenso sofrimento vivido: "When I saw my image on TV, I was very tormented"15 (28:35).

No dia seguinte, sábado, o médico veio lhe dizer que o primeiro teste teve resultado negativo para o vírus Ebola, explicando que repetiriam o exame no dia seguinte e, se o resultado fosse novamente negativo, poderia ir embora. Domingo, o médico apareceu sem a roupa de proteção:

Late in the afternoon the doctor came. All the doctors, the sisters, everybody. They said: "Do you see us? Normal clothes! You are no more Ebola suspect, you are free!” They were all happy, singing and crying ${ }^{16}$ (31:36).

\footnotetext{
14 "Vi minha imagem na TV, como me colocaram na ambulância. Usaram minha foto, vi meu protocolo. Depois, desliguei a televisão. Eu não queria assistir aquilo." 15 "Quando vi minha imagem na TV, fiquei muito atormentado."

16 "No final da tarde o médico veio. Todos os médicos, as irmãs [provavelmente John refere-se às enfermeiras], todos. Eles disseram: 'você está nos vendo? Roupas normais! Você não está mais com suspeita de Ebola, você está livre!'. Estavam todos felizes, cantando e chorando."
} 
Como seus sintomas e especialmente os resultados dos primeiros exames justificavam uma suspeita de câncer, fez novos exames. O diagnóstico final foi de deficiência de vitamina B. Soube que sua língua estava escura como um efeito colateral do remédio que tomou para a malária na África. John fez questão de nos mostrar diversas vezes as cópias de seu prontuário do INI-Fiocruz. Fica evidente o quanto é importante para ele repetir que não teve Ebola e que não havia razão alguma para que se pensasse que ele estava com Ebola.

John assistiu na televisão a entrevista do médico, explicando que os resultados deram negativo. Soube que os jornalistas queriam entrevistá-lo, mas se negou a falar, pois temia que o governo de seu país soubesse que estava no Brasil. Também se encontrava preocupado com a família. Seu primeiro pedido ao sair do hospital foi o de entrar em contato com seu irmão para avisá-lo que estava bem. Temia que os familiares vissem nos jornais, pela internet, que ele havia sido internado com suspeita de Ebola e, por não ter mais notícias, pensassem que havia morrido.

Antes de sua liberação, a equipe do INI-Fiocruz perguntou se John gostaria de voltar a Cascavel ou preferiria permanecer no Rio de Janeiro. Não queria voltar a Cascavel, pois sua imagem estava em todos os jornais. Viu na televisão notícias sobre a violência no Rio de Janeiro. Pediu então para ir para São Paulo, pois ouviu de conterrâneos guineenses que lá haveria maior chance de emprego.

No dia da partida, o médico e as enfermeiras estavam emocionados; alguns choraram, tiraram fotos juntos, estavam muito felizes. Na viagem entre o Rio de Janeiro e São Paulo, disseram-lhe que o chamariam de John, para evitar que o reconhecessem na rua. É a razão pela qual ele escolheu esse nome para identificá-lo no presente artigo.

Neste momento é que Ana e John se conheceram. Ana conta que o traslado de John foi considerado, no Ministério 
da Saúde (MS), uma espécie de "missão impossível”, pois os protocolos nada dizem sobre o que fazer com o caso suspeito não confirmado. Ajudá-lo a sair do hospital e mudar de cidade foi uma iniciativa dos funcionários do Ministério da Saúde, que se sensibilizaram com a situação de John: "se sentiam na obrigação de ajudar, como seres humanos. Queriam minimizar os prejuízos sofridos por John" (Ana, 2015, 29:43).

Segundo Ana, em caráter de urgência, MS e Fiocruz conceberam uma estratégia para retirar John do INI-Fiocruz em segurança e fizeram contato com a organização Caritas Arquidiocesana de São Paulo, que possui um Centro de Referência para Refugiados na cidade e se dispôs a acolhê-lo. Optaram pelo deslocamento em automóvel, pois pensaram: "se o levarmos de avião, a foto dele está em todo canto, vai chover repórter! Também seria difícil embarcar, as companhias aéreas perceberiam que se trata dele. Por 124 isso, decidimos usar um carro" (22:18).

Ana relata que John aparentava estar um pouco assustado e com sinais de fraqueza, acredita que em decorrência da fuga do seu país e da situação que encontrou ao chegar ao Brasil: "ele tinha consciência que estava debilitado. Estava magro, parecia malnutrido. Ao trocar de roupa, dava para perceber a perda de peso drástica” (11:51).

Chegando ao INI-Fiocruz na segunda-feira, Ana conversou com autoridades da Fiocruz para definir os detalhes. Na quinta-feira, às 5 h30 da manhã, deixaram o local pela portaria lateral, e não pela saída principal. O carro não era identificado, sem placa diferenciada ou dizeres na lateral. Na opinião de Ana, "a preocupação em preservá-lo da imprensa foi do MS. John não tinha consciência da dimensão do que lhe aconteceu. Ele vivia uma história surreal” (26:02).

Na viagem entre Rio e São Paulo, John contou sobre sua vida e a perseguição que sofreu, e que a única oportunidade de sobrevivência era sair da Guiné e vir ao Brasil. 
Segundo Ana, ele disse que foi ao posto de saúde em Cascavel porque estava com fraqueza e sem apetite. Sentiu algo que poderia ser febre, mas não sabia se era. Ao chegar ao posto de saúde, como as pessoas não compreendiam o que falava, ele foi mal interpretado. Só no Rio de Janeiro foi comunicado sobre a suspeita de Ebola: "imagino que seja traumatizante, de repente te colocam no avião, completamente encapado com aquela roupa, como se fosse um terrorista, e não tinha nada a ver com isso" expressa Ana (15:07).

Na opinião dela, não houve discriminação no atendimento de John em Cascavel. Acredita que houve "um susto" por parte do pessoal da UPA, pois o episódio ocorreu no auge da repercussão internacional da epidemia. Afirma que "a Secretaria de Saúde do Paraná é muito ativa, mas a parte assistencial foi falha, tanto que o documento dele vazou" (32:21). Ana considera que John foi bem tratado em Cascavel, "mas não foi informado do que estava acontecendo. Houve uma dificuldade na comunicação, foi um ponto falho. $\mathrm{O}$ fato de não terem conversado com o John e explicado o que estava acontecendo foi um problema" (14:37). Ela ressalta que "a discriminação foi sofrida por aqueles que ficaram no Paraná. John vivia no albergue com outras pessoas, os colegas dele devem ter sofrido após publicarem sobre a suspeita de Ebola" (27:56).

Depois de deixá-lo em São Paulo, o Ministério da Saúde não teve mais contato com John, que passou a ser acompanhado pela Caritas. John conseguiu reaver a mala que estava no albergue em Cascavel.

Perguntada se sabia quem divulgou o documento de John, Ana disse desconhecer, mas ressaltou que a foto foi publicada antes de ele sair de Cascavel. "A violação à privacidade do paciente foi completamente contra os códigos de ética”, assevera Ana (18:41). Até o dia em que concluímos o presente artigo, era possível encontrar no jornal 
Folha de S.Paulo on-line uma galeria de fotos realizadas por um fotojornalista em Cascavel, que revela o momento em que John é colocado na ambulância que o transportou da UPA ao aeroporto. A análise combinada das fotos 13 e 14 dessa galeria permitem identificar a pessoa, apresentada pelo jornal como "funcionário da Prefeitura de Cascavel", e o momento em que apresenta cópia em preto e branco do protocolo de refúgio de John aos jornalistas (Cruz, 2014). Outros vazamentos certamente ocorreram, pois a mídia chegou a apresentar cópia do passaporte de John (Paciente que..., 2014), enquanto os telejornais da Rede Globo exibiam sua foto colorida (por ex., o G1: Após suspeita de Ebola..., 2014).

Não resta dúvida sobre a ilegalidade da difusão da imagem e da identidade de John. A Lei n ${ }^{\circ}$ 9.474/97, que implementa o Estatuto dos Refugiados no Brasil, garante o sigilo sobre as informações fornecidas e a confidencialidade da tra126 mitação da solicitação de refúgio (Brasil, 1997, arts. 20 e 23). Tampouco o direito sanitário ampara essa difusão. A Portaria $\mathrm{n}^{\circ} 1.271$, de 2014, do MS assegura que: "as autoridades de saúde garantirão o sigilo das informações pessoais integrantes da notificação compulsória que estejam sob sua responsabilidade (Brasil/MS, 2014, art. 7). A já citada lei sobre a vigilância epidemiológica, por sua vez, estipula que "a notificação compulsória de casos de doenças tem caráter sigiloso, obrigando nesse sentido as autoridades sanitárias que a tenham recebido" (Brasil, 1975, art. 10), elucidando que

A identificação do paciente de doenças referidas neste artigo, fora do âmbito médico sanitário, somente poderá efetivar-se, em caráter excepcional, em caso de grande risco à comunidade a juízo da autoridade sanitária e com conhecimento prévio do paciente ou do seu responsável (Brasil, 1975, art. 10, parágrafo único). 
No mesmo sentido, a Portaria $\mathrm{n}^{0} 1.820$, de 2009, considera a confidencialidade de toda e qualquer informação pessoal um direito da pessoa (Brasil/MS, 2009, art. 4, parágrafo único, alínea e), sendo dever do sistema de saúde manter o sigilo e a confidencialidade de todas as informações pessoais, mesmo após a morte, salvo nos casos de risco à saúde pública (art. $5^{\circ}$, II).

Deve ser destacado que o Ministério da Saúde e as secretarias de saúde, respectivamente estadual e municipal, do Paraná e de Cascavel, não divulgaram oficialmente a identidade de John. Não houve, portanto, avaliação de que ela seria necessária para coibir riscos. É preciso esclarecer, ainda, que a permissão legal para difusão de identidade de um paciente não significa a transmissão desses dados para a imprensa. Ao contrário, o serviço de saúde que detém essa informação possui

[...] o dever de atuar no estrito âmbito da discrição esperada, de modo que a adoção dos cuidados e condutas epidemiológicas que motivaram a inclusão do quadro patológico entre tais situações de notificação obrigatória não representem uma exposição desnecessária e uma fonte de discriminação e coerção do paciente (Villas-Bôas, 2015, p. 521; tradução das autoras $)^{17}$.

A divulgação da imagem de John foi oficiosa e suscitou duras críticas na área da saúde pública. Poderíamos sintetizá-las nos seguintes aspectos: culpa-se a vítima [John] em lugar de protegê-la; pessoas podem deixar de buscar ou buscar tardiamente a assistência por temor à exposição em

\footnotetext{
17 “[...] el deber de actuar en el estricto ámbito de la discreción esperada, de modo que la adopción de los cuidados y conductas epidemiológicas que motivaron la inclusión del cuadro patológico entre tales situaciones de notificación obligatoria no representen una exposición innecesaria y una fuente de discriminación y constreñimiento al paciente".
} 
noticiários de tevê e jornais; o pânico dificulta o trabalho de investigação de contatos, pois possíveis casos suspeitos podem não se apresentar às estruturas de saúde por receio de isolamento; a população deveria ser encorajada a manter a calma, pois a transmissão da doença somente se dá pelo contato com sangue, órgãos, fluidos corporais ou secreções (fezes, urina, saliva, sêmen, vômito, sangue); a ênfase da repercussão não deveria repousar sobre um caso suspeito, e sim na capacidade do sistema, por exemplo, de verificar se há Equipamento de Proteção Individual (EPI) em todos os níveis das estruturas, dos mais periféricos aos mais especializados etc. (Pesquisadores da ENSP..., 2014).

O plano de contingência para a doença por Ebola, na seção "Estratégias de comunicação", prevê a diretriz de "manter a população informada, tranquila e evitar reações sociais contra os pacientes", além de responder a boatos e mensagens nas redes sociais "que causem pânico" (Brasil/ 128 MS/SVS, 2014, p. 56). Independentemente do sucesso dessa estratégia, a garantia da confidencialidade protege o paciente de pressões externas que possam lhes ser constrangedoras e permite que ele julgue as suas próprias circunstâncias, sem temer a repercussão que suas decisões pessoais em matéria de saúde possa causar no meio social (Villas-Bôas, 2015).

Não foi o que ocorreu com John. Ele não pôde retornar à Cascavel e retomar sua busca por emprego. No momento de nossa entrevista, encontrava-se desempregado. Temendo a discriminação e até o linchamento, ele foi abrigado, desde outubro de 2014, em uma instituição católica na cidade de São Paulo. Como muçulmano, ele se esforça para conviver com os hábitos de outra religião. Sendo a instituição afastada do centro da cidade, ele disse padecer de tédio e isolamento, de falta de privacidade por compartilhar um alojamento coletivo e de dificuldade de deslocamento para procurar emprego. Sua alegria são as aulas de português. 
Nas conversas com os companheiros de abrigo, teme que a suspeita de Ebola seja evocada. Quando sua procedência da Guiné suscita essa suspeita, ele se sente obrigado a mentir, dizendo que há muitos homônimos em seu país.

Uma vez excluída a suspeita de Ebola, em 13 de outubro de 2014, as autoridades não tomaram nenhuma providência para que o nome verdadeiro de John fosse retirado da internet e das redes sociais. Ele está convicto de que a persistência da exposição de suas fotos e documentos em numerosos veículos de comunicação é o maior obstáculo para que consiga um emprego. No momento em que o encontramos, estávamos diante de uma pessoa em evidente sofrimento, com sinais de prostração e de angústia, que afirma ter como sonho um emprego e um quarto individual. Meses depois do evento, ele ainda era "o africano" e o "refugiado negro" que foi o primeiro caso suspeito de Ebola no Brasil.

\section{Amálgama entre "estrangeiro" e "doença": estigmatização de migrantes e refugiados}

Segundo Quentin Crisp, "a saúde consiste em ter as mesmas doenças que os seus vizinhos" (apud Clatts e Mutchler, 1989, p. 105). Esse enunciado traduz de forma simples a ideia de que a epidemia se apresenta sempre como um "perigo vindo de longe", ou pela "figura fantasmática do estrangeiro ameaçador que seria o seu vetor" ou "sob a forma aparentemente mais neutra de que os movimentos das populações a favoreceria" (Fassin, 2001, p. 137). Mas a doença, em geral, não é a causa do estigma:

[...] as grandes massas de homens veem as grandes massas de homens vizinhos segundo as regras de uma ótica particular, que não as embeleza: elas não distinguem suas nuanças; elas simplificam informações incompletas numa síntese grosseira, elas criam tipos coletivos. Esses 
tipos, ingenuamente esquemáticos, assombram a partir do momento em que são fixados no imaginário popular (Langlois, 1893, p. 299).

Desse modo, a doença vem preencher um "espaço de desqualificação preexistente" do estrangeiro (Fassin, 2001, p. 137).

Em agosto e setembro de 2014, portanto antes que ocorresse a primeira suspeita no Brasil, o Ebola já ensejava a estigmatização de migrantes e refugiados. Técnicos da Polícia Federal, da Receita Federal e do Ministério do Trabalho e Emprego cogitaram paralisações ou greves para evitar o contato com migrantes negros chegados na região Norte do país (Sampaio, 2014; Sanches, 2014).

No caso de John, a mídia brasileira referiu-se a ele como o "africano". Eis alguns exemplos do noticiário:

- O Estado de S. Paulo: Sangue de africano com suspeita de Ebola já foi enviado para novo teste. 12 out. 2014.

- O Globo: Perfil no Facebook de africano suspeito de ter Ebola no Brasil vira alvo de ataques de brasileiros. 10 out. 2014.

- Fantástico (Rede Globo): Africano com suspeita de Ebola esperou por 4 horas até ser atendido. 12 out. 2014

- Terra: Africano com suspeita de Ebola passou por SP, SC e Argentina. 10 out. 2014.

- Tribuna Paraná Online: Africano Souleymane teme agora retornar a Cascavel. 14 out. 2014.

- UOL: Africano com suspeita de Ebola teve contato com 64 pessoas no Brasil. 10 out. 2014.

Um estudo específico sobre a cobertura do caso pelo jornal Folha de S.Paulo concluiu que houve "a construção do estereótipo do imigrante guineense" a partir da lógica do risco, "reforçando a generalizada consideração da África 
como lugar de risco para a saúde pelo surto do Ebola e dos africanos como agentes disseminadores da doença" (Sacramento e Machado, 2015, p. 43). Assim,

[...] o jornal reforça a conexão entre a cultura africana e o Ebola. Essa associação é mais do que uma retórica de transformação da doença numa questão étnica, uma vez que constrói a africanidade como um fator de risco à saúde. Por diversas vezes, como analisamos, as matérias incitavam o pânico, relacionando a origem africana de [...] [John] à suspeita de contaminação por Ebola (idem, ibidem).

Sacramento e Machado (p. 44) sublinham que o episódio ocorreu "num contexto de acirrada campanha eleitoral para presidente no Brasil", e que o jornal teve de reconhecer "a eficácia do dispositivo de segurança sanitária do governo brasileiro, mas, tacitamente, demoniza a presença de africanos no Brasil". Embora as autoridades sanitárias tenham negado a possibilidade de surto de Ebola no país, o jornal reforçou a necessidade do estado de alerta: "não houve espaço para promover a compaixão pelo imigrante, mas houve demasiado para promover o medo e a necessidade de dispositivos de segurança" (idem, ibidem).

As repercussões desse tipo de abordagem não tardaram a surgir, atingindo igualmente os migrantes negros provenientes de outras regiões, em particular os haitianos. No Paraná, africanos e haitianos foram hostilizados (Cambricoli, 2014). Em Cascavel, o presidente da Associação de Migrantes Haitianos relatou:

Os haitianos estão com medo, vários vieram falar comigo e pediram para explicar a diferença entre haitiano e africano e que não temos epidemia de Ebola no nosso país. Peço para eles ficarem mais quietos, enquanto o medo das pessoas não passa, para não falarem muito (Paciente que teve..., 2014). 
Esse amálgama foi tão significativo que em estudo do tratamento dado à imigração de haitianos pela mídia brasileira nos primeiros quatro anos de presença significativa da diáspora haitiana no país (2011-2014), Denise Cogo e Terezinha Silva consideram o Ebola um dos sete principais temas da agenda midiática relacionada aos haitianos (Cogo e Silva, 2016). Considerando a ausência de notícias sobre hostilização de migrantes ou turistas brancos, independentemente de sua procedência, a negritude aparece como provável explicação para a discriminação de haitianos.

Nas entrevistas coletivas organizadas no auge da resposta ao primeiro caso suspeito de Ebola no Brasil, com ampla repercussão nos meios de comunicação, inclusive transmissão direta por emissoras de televisão, o à época Ministro da Saúde, o médico sanitarista Arthur Chioro, identificou esse amálgama: "Eu repudio as manifestações racistas que foram feitas. Em pleno século XXI isso é inaceitável. Achar que o 132 Ebola tem a ver com a dimensão racial é inaceitável" (Ministro da Saúde presta mais esclarecimentos..., 2014). Questionado por jornalistas sobre a necessidade de fechamento das fronteiras brasileiras, respondeu que "o resultado dessa ação seria contraproducente, já que a entrada ilegal de pessoas poderia aumentar”, afirmando ainda que ninguém seria deportado em razão de possíveis sintomas da doença. No entanto, a experiência da violação dos direitos de John não foi suficiente para que uma nova legislação epidemiológica respeitosa dos direitos humanos fosse adotada, tampouco para que o plano de contingência relativo ao Ebola passasse a incorporar a perspectiva dos direitos do paciente.

Outras instituições republicanas demonstraram sua preocupação com a efetividade dos direitos humanos em situação de emergência sanitária. O Ministério Público Federal (MPF) no Distrito Federal enviou recomendação à Polícia Federal e à Secretaria Executiva do Ministério da Saúde solicitando a adoção de providências para assegurar 
o sigilo de dados pessoais de hospitalizados com a suspeita de infecção pelo vírus Ebola no Brasil (MPF/DF, 2014). Foram ainda encaminhadas representações criminais ao Ministério Público Federal no Estado do Rio de Janeiro (MPF/RJ) e ao Ministério Público do Estado do Paraná no Município de Cascavel, assim como uma representação ao CFM. Os documentos solicitaram a apuração do vazamento de informações confidenciais do paciente e a imposição de sanções disciplinares e penais aos responsáveis. Como fundamentos para tais providências, o MPF apontou tanto os direitos individuais (proteção do paciente) como o direito coletivo (proteção à saúde pública):

[...] em razão do intenso interesse demonstrado pela população e da imprensa pelo caso, novos vazamentos de informações pessoais e hostilidades poderão ocorrer contra outros hospitalizados com suspeita de contágio do vírus Ebola. O receio de sofrer agressões físicas ou verbais pode fazer com que as pessoas ocultem a doença, não procurando assistência médica e causando grave risco à saúde pública (MPF/DF, 2014).

No mesmo diapasão, a Defensoria Pública da União (DPU), cujas atribuições incluem a assistência a refugiados estrangeiros no Brasil, recomendou ao Ministério da Saúde que oriente seus agentes a manter o sigilo da identidade e da imagem de pessoas suspeitas de infecção pelo vírus Ebola no país, e igualmente oriente a imprensa sobre como proceder nesses casos, sob os argumentos de que:

[...] mostra-se imperioso que se preservem os direitos fundamentais de qualquer pessoa suspeita de estar contaminada pelo vírus, notadamente pelo fato de ser suspeita, ou seja, de não ter sido confirmada a contaminação, e ainda, para evitar pânico na sociedade, inclusive 
estimulando que pessoas eventualmente contaminadas deixem de informar as suas condições físicas com medo e receio de uma retaliação, preconceito e exposição desarrazoada de sua imagem e honra (DPU, 2014).

\section{$* * *$}

Nosso artigo evidenciou o grande potencial de impacto da crise sanitária gerada pelo vírus Ebola sobre os direitos humanos, mesmo fora do epicentro da epidemia. A existência de um sistema público de saúde, cujo acesso é universal e gratuito, mostra-se fundamental para que os Estados possam dar uma resposta satisfatória às emergências internacionais. $\mathrm{O}$ caso estudado corrobora a ideia de que o acesso de migrantes e refugiados ao sistema público de saúde é fundamental para o controle de epidemias, e de que a correta

134 implementação do Regulamento Sanitário Internacional (RSI), que exige o fortalecimento dos sistemas nacionais de saúde, é a melhor resposta para os riscos que a mobilidade humana aporta para a saúde global (Ventura, 2015).

No entanto, a norma que deveria ser um "escudo" de proteção dos direitos pode transformar-se em "arma" contra eles, pois o acesso ao tratamento tende a se converter em fonte de violação dos direitos individuais se não houver uma regulação capaz de oferecer salvaguardas quando da adoção de medidas coercitivas pela autoridade sanitária. Logo, é preciso que a legislação epidemiológica e os planos de contingência passem a contemplar mecanismos de proteção aos direitos humanos. $\mathrm{O}$ desafio de conciliar a saúde pública e as liberdades individuais é complexo, mas deixar de enfrentá-lo aumenta a possibilidade de que a escalada do pânico nos momentos de crise sanitária enseje violações evitáveis, porém graves e de efeitos duradouros. Ademais, é preciso fomentar uma cultura de direitos humanos que 
favoreça o cumprimento das normas protetivas já existentes, como é o caso do sigilo sobre a identidade do paciente.

Por fim, o caso de John concede-nos uma pequena amostra dos riscos trazidos por propostas, normas e estudos sobre os sistemas de vigilância em saúde que não levam em consideração o impacto real de sua implementação sobre a vida das pessoas.

\section{Deisy Ventura}

é professora do Instituto de Relações Internacionais e da Faculdade de Saúde Pública da USP; bolsista de Produtividade em Pesquisa do CNPq.

\section{Vivian Holzhacker}

é mestre em Direito Internacional dos Direitos Humanos pela Universidade de Connecticut (EUA); foi Coordenadora de Proteção e Advogada da Caritas Arquidiocesana de São Paulo (2011-2014) e consultora do Alto Comissariado da ONU para Refugiados (Acnur) (2015).

\section{Bibliografia}

AFRICANO com suspeita de Ebola esperou por 4 horas até ser atendido. 2014. Fantástico, Rede Globo. 12 out. Disponível em: <http://g1.globo.com/fantastico/noticia/2014/10/africano-comsuspeita-de-ebola-esperou-por-4-horas-ate-ser-atendido.html >. Acesso em: 28 fev. 2016.

AFRICANO com suspeita de Ebola passou por SP, SC e Argentina.

2014. Terra. 10 out. Disponível em: <http://noticias.terra.com.br/ brasil/africano-com-suspeita-de-ebola-passou-por-sp-sc-e-argentina,2 187befdeeaf8410VgnVCM4000009bcceb0aRCRD.html>. Acesso em: 28 fev. 2016.

AFRICANO com suspeita de Ebola teve contato com 64 pessoas no Brasil. 2014. UOL. 10 out. Disponível em <http://noticias.uol.com.br/saude/ ultimas-noticias/efe/2014/10/10/africano-com-suspeita-de-ebola-tevecontato-com-64-pessoas-no-brasil.htm>. Acesso em: 28 fev. 2016.

AFRICANO Souleymane teme agora retornar a Cascavel. 2014. Tribuna Paraná [on-line]. Cidades. 14 out. 
AITH, F.; DALLARI, S. 2009. Vigilância em saúde no Brasil: os desafios dos riscos sanitários do século XXI e a necessidade de criação de um sistema nacional de vigilância em saúde. Revista de Direito Sanitário, v. 10, n. 2, pp. 94-125.

APÓS suspeita de Ebola, haitianos enfrentam preconceito em Cascavel. 2014. G1 [Globo]. 14 out. Disponível em: <http://g1.globo.com/pr/ oeste-sudoeste/noticia/2014/10/apos-suspeita-de-ebola-haitianosenfrentam-preconceito-em-cascavel.html>. Acesso em: 28 fev. 2016.

ARMED Conflict Location and Event Data Project. 2015. Guinea. ACLED Conflict Trends, n. 43.

BÉLGICA, FRANÇA, SUÍÇA. 2012. Rapport de mission en République de Guinée 29 octobre - 19 novembre 2011. Mission organisée conjointement par le CGRA (Belgique), l'OFPRA (France) et l'ODM (Suisse), March. BRASIL. 1975. Lei ${ }^{\circ}$ 6.259, de 30 de outubro. Dispõe sobre a organização das ações de Vigilância Epidemiológica, sobre o Programa Nacional de Imunizações, estabelece normas relativas à notificação compulsória de doenças, e dá outras providências.

BRASIL. 1990. Lei $n^{\circ}$ 8.080, de 19 de setembro. Dispõe sobre as condições para a promoção, proteção e recuperação da saúde, a organização e o funcionamento dos serviços correspondentes e dá 136 outras providências. 1997. Lei n ${ }^{\circ} 9.474$, de 22 de julho. Define mecanismos para a implementação do Estatuto dos Refugiados de 1951, e determina outras providências.

2011. Decreto $\mathrm{n}^{\circ}$ 7.616, de 17 de novembro. Dispõe sobre a declaração de Emergência em Saúde Pública de Importância Nacional - Espin, e institui a Força Nacional do Sistema Único de Saúde FN-SUS.

BRASIL/MS. Ministério da Saúde. 2007. Carta dos direitos dos usuários da saúde. 2. ed. Brasília, DF: Ministério da Saúde.

. 2009. Portaria $\mathrm{n}^{\circ} 1.820$, de 13 de agosto. Dispõe sobre os direitos e deveres dos usuários da saúde.

2014. Portaria $n^{\circ} 1.271$, de 6 de junho. Define a Lista Nacional de Notificação Compulsória de doenças, agravos e eventos de saúde pública nos serviços de saúde públicos e privados em todo o território nacional, nos termos do anexo, e dá outras providências.

BRASIL/MS/SVS. 2014. Ministério da Saúde. Secretaria de Vigilância em Saúde. Departamento de Vigilância das Doenças Transmissíveis. Plano de Contingência para Emergência em Saúde Pública - Doença pelo Vírus Ebola. Versão 17. Brasília, DF: Ministério da Saúde. 
2016. Investigação de caso suspeito de doença pelo vírus Ebola no município de Cascavel/Paraná, outubro de 2014. Boletim Epidemiológico, v. 47 , n. 17 , pp. $1-7$.

CAMBRICOLI, F. 2014. Africanos e haitianos são hostilizados no PR após suspeita de Ebola. O Estado de S. Paulo. Saúde, 13 out.

CANADÁ. 2014. Immigration and Refugee Board - Guinea: ethnic composition of police and military forces; treatment of Peul by authorities, including police and military, and in cases where a Peul individual requires State protection (2009-May 2014). GIN104870, 7 Nov.

CERBINO NETO, J. 2014. Questões éticas no manejo de pacientes com doença pelo vírus Ebola. Cadernos de Saúde Pública, v. 30, n. 11, pp. 2256-58.

CLATTS, M.; MUTCHLER, K. 1989. Aids and the dangerous other: metaphors of sex and deviance in the representation of disease. Medical Anthropology, n. 10, pp. 105-114.

COGO, D.; SILVA, T. 2016. Entre a fuga e a invasão: alteridade e cidadania da imigração haitiana na mídia brasileira. Revista Famecos - Mídia, Cultura e Tecnologia, Porto Alegre, v. 23, n. 1. Disponível em: <http:/ / revistaseletronicas.pucrs.br/ojs/index.php/revistafamecos/article/ viewFile/21885/13676>. Acesso em: 17 abr. 2016.

CONSELHO Federal de Medicina. 2009. Resolução no 1.931. Aprova o Código de Ética Médica. Brasília, 17 set.

CRUZ, L. C. 2014. Fotos. Paciente com suspeita de Ebola é transferido para o Rio de Janeiro. Folha de S.Paulo, 10 out. Disponível em: <http://www1.folha.uol.com.br/cotidiano/2014/10/1530277paciente-com-suspeita-de-ebola-e-transferido-ao-rio-de-janeiro.shtml $>$. Acesso em: 17 abr. 2016.

DEFENSORIA PÚBLICA DA UNIÃO. 2014. DPU recomenda preservação da identidade de pessoas com suspeita de Ebola. 20 out.

DELGADO, P. 2012. Internação involuntária: implicações éticas, clínicas e legais. Ciência Hoje, v. 50, n. 295, pp. 78-79.

DIAS, R. 2015. Derechos fundamentales de los pacientes al fin de la vida: de la ética médica al proyecto de código penal brasileño. BioLaw Journal - Rivista di BioDiritto, n. 3, pp. 99-116.

ESTADOS UNIDOS. Bureau of Democracy, Human Rights and Labor. 2015. Country Reports on Human Rights Practices for 2014 - Guinea. Washington, DC, May.

FASSIN, D. 2001. Une double peine - La condition sociale des immigrés malades du sida. L'Homme, v. 4, n. 160, pp. 137-62. 
FERREIRA, V. S. 2014. Artes e manhas da entrevista compreensiva. Saúde e Sociedade, São Paulo, v. 23, n. 3, pp. 979-92.

GOMES, A. et al. 2008. Código dos direitos e deveres da pessoa hospitalizada no SUS: o cotidiano hospitalar na roda de conversa. Interface, Botucatu, v. 12, n. 27, pp. 773-82.

KAUFMANN, J.-C. 2013. A entrevista compreensiva: um guia para a pesquisa de campo. Petrópolis/Maceió: Vozes/Edufal.

KENTIKELENIS, A. et al. 2015. The International Monetary Fund and the Ebola outbreak, The Lancet, Global Health, v. 3, n. 2, e-69-e70.

KEROUEDAN, D. 2015. Les bonnes pratiques de la "global health": améliorer la santé ou bien gérer l'argent? In: KLEIN, A.; LAPORTE, C.; MARIE, C. (dirs.). Les bonnes pratiques des organisations internationales. Paris: Presses de Sciences Po.

LANGLOIS, C.-V. 1893. Les anglais du Moyen Âge d'après les sources françaises. Revue Historique, t. 52, fasc. 2, pp. 298-315.

MATTHEY, L. 2005. Éthique, politique et esthétique du terrain: cinq figures de l'entretien compréhensif. Cybergeo: European Journal of Geography, n. 312. Disponível em: <DOI: 10.4000/cybergeo.3426>.

MINISTRO da Saúde presta mais esclarecimentos sobre o caso de suspeita de Ebola. 2014. Portal Brasil. 11 out. Disponível em: <http://www.brasil. gov.br/saude/2014/10/ministro-da-saude-presta-mais-esclarecimentossobre-o-caso-de-suspeita-de-ebola>. Acesso em: 28 fev. 2016.

$\mathrm{MPF} / \mathrm{DF}$ quer assegurar sigilo de pacientes com suspeita de Ebola no Brasil. MPF - Ministério Público Federal. 2014. 17 out. Disponível em: <http:/ / www.mpf.mp.br/df/sala-de-imprensa/noticias-df/mpf-df-querassegurar-o-sigilo-de-dados-pessoais-de-pacientes-que-surgirem-comsuspeita-de-ebola-no-brasil>. Acesso em: 17 abr. 2016.

NIANG, C. I. 2014. Ebola: une épidémie postcoloniale. Politique étrangère, n. 4 , pp. 97-109.

OMS - Organização Mundial de Saúde. 2009. Regulamento Sanitário Internacional (2005). Versão em português aprovada pelo Congresso Nacional por meio do Decreto Legislativo no 395/2009. Brasília: Agência Nacional de Vigilância Sanitária. Disponível em: <http:/ /www. anvisa.gov.br/hotsite/viajante/Regulamento_Sanitario_Internacional_ vers \% C3\%A3o\%20para\%20impress \% C3\%A3o.pdf>. Acesso em: 15 abr. 2016.

2014. Statement on the 1st meeting of the IHR Emergency Committee on the 2014 Ebola outbreak in West Africa. 8 ago.

2016a. Statement on the 9th meeting of the IHR Emergency Committee regarding the Ebola outbreak in West Africa. 29 mar. 
2016b. Ebola situation report. 30 mar. Disponível em: <http:/ / apps.who.int/ebola/current-situation/ebola-situation-report-30march-2016>. Acesso em: 15 abr. 2016.

PACIENTE que poderia ter Ebola deixa isolamento. 2014. band.com.br. 13 out. Disponível em: <http://noticias.band.uol.com.br/cidades/ noticia/?id=100000713770\&t=>. Acesso em: 28 fev. 2016.

PACIENTE que teve suspeita de Ebola sai de isolamento em hospital no Rio. 2014. G1. 13 out. Disponível em: <http://g1.globo.com/rio-dejaneiro/noticia/2014/10/paciente-que-teve-suspeita-de-ebola-sai-deisolamento-em-hospital-do-rio.html>. Acesso em: 28 fev. 2016.

PERFIL no Facebook de africano suspeito de ter Ebola no Brasil vira alvo de ataques de brasileiros. 2014. O Globo. Saúde. 10 out. Disponível em: <http://oglobo.globo.com/sociedade/saude/perfil-no-facebookde-africano-suspeito-de-ter-ebola-no-brasil-vira-alvo-de-ataques-debrasileiros-14206836>. Acesso em: 28 fev. 2016.

PESQUISADORES da ENSP comentam suspeita de Ebola no país. 2014. Informe ENSP. 10 out.

PROTOCOLO internacional é adotado em suspeita de caso de Ebola em Cascavel. 2014. Agência de Notícias do Paraná. 10 out.

SACRAMENTO, I.; MACHADO, I. B. 2015. A imigração como risco para a saúde: uma análise das representações do imigrante africano na cobertura da Folha de S.Paulo sobre o Ebola. Comunicação e Sociedade, n. 28 , pp. 25-47.

SAMPAIO, L. 2014. Acre pede ajuda a governo federal para evitar que vírus do Ebola entre no país. Folha de S.Paulo. 30 ago.

SANCHES, M. 2014. Com medo do Ebola, agentes da PF no Acre barram africanos que chegam em onda migratória. $O$ Globo. 9 set.

SANGUE de africano com suspeita de Ebola já foi enviado para novo teste. 2014. O Estado de S. Paulo. Saúde. 12 out.

SANTOS, I.; NASCIMENTO, W. 2014. As medidas de quarentena humana na saúde pública: aspectos bioéticos. Revista Bioethikos, São Paulo, v. 8, n. 2, pp. 174-85.

UNIÃO EUROPEIA. 2013. Mission d'observation électorale de l'UE en République de Guinée - Rapport final - élections législatives, 28 Sept. VENTURA, D. 2013. Direito e saúde global - o caso da pandemia de gripe A(H1N1). São Paulo: Dobra Editorial/Expressão Popular. . 2015. Mobilidade humana e saúde global. Revista USP, n. 107, pp. 55-64.

VILLAS-BÔAS, M. E. 2015. O direito-dever de sigilo na proteção ao paciente. Revista Bioética, v. 23, n. 3, pp. 513-23. 
Saúde global e direitos humanos: o primeiro caso suspeito de Ebola no Brasil

WANSSA, M. C. 2011. Autonomia versus beneficência. Revista Bioética, v. 19, n. 1, pp. 105-17.

\section{Depoimentos}

ANA. 2015. Depoimento. Entrevistadoras: Deisy de Freitas Lima Ventura e Vivian Holzhacker. Brasília/São Paulo, 2 out. 1 arquivo .mp3 (37:50 min.).

JOHN. 2015. Depoimento. Entrevistadoras: Deisy de Freitas Lima Ventura e Vivian Holzhacker. São Paulo, 16 jul. 1 arquivo .mp3 (55:01 min.). 


\section{SAÚDE GLOBAL E DIREITOS HUMANOS: O PRIMEIRO CASO SUSPEITO DE EBOLA NO BRASIL}

\section{DEISY VENTURA}

\section{VIVIAN HOLZHACKER}

Resumo: $\mathrm{O}$ artigo avalia o impacto da crise sanitária internacional do Ebola sobre os direitos de um solicitante de refúgio que foi considerado o primeiro caso suspeito da doença no Brasil, em outubro de 2014. O estudo do caso foi conduzido sob o prisma do paciente, entrevistado em julho de 2015. Foi entrevistada, ainda, uma servidora pública que acompanhou o paciente à época. Foram estudados documentos oficiais, literatura especializada e notícias veiculadas pela mídia, além da legislação e da doutrina jurídica. O texto aborda as violações aos direitos de informação e consentimento do paciente; demonstra que a ampla difusão de sua identidade e de sua imagem constituem flagrantes violações do direito sanitário e do direito dos refugiados; por fim, apresenta a repercussão do caso sobre os direitos dos migrantes e algumas respostas institucionais que ele suscitou.

Palavras-chave: Saúde Global; Ebola; Direitos Humanos; Direito dos Refugiados.

\section{GLOBAL HEALTH AND HUMAN RIGHTS: THE FIRST SUSPICIOUS CASE OF EBOLA IN BRAZIL}

Abstract: The article analyzes the impact of Ebola international sanitary crisis on the rights of an asylum seeker, which was considered the first case of Ebola suspicion in Brazil, during October 2014. The case study was conducted focused on the patient's view, who was interviewed in July 2015. A public servant who was with the patient by then was also interviewed. Official documents, specialized literature and news were also studied, as well as legislation and 
doctrine. The paper studies violations to the information and consent rights of the patient; shows that the wide diffusion of his semblance and name constituted a flagrant violation of the sanitary and asylum rights; finally, it presents the case repercussion over migrant's rights and institutional answers it created.

Keywords: Global Health; Ebola; Human Rights; Refugee Law.

Recebido em: 24/4/2016 Aprovado em: 17/6/2016 